RESEARCH ARTICLE

\title{
Strategic Approaches for Outdoor Cultivation of Paddy Straw Mushroom (Volvariella volvacea) as Intercrop Under different Cropping Systems
}

\author{
G. Thiribhuvanamala ${ }^{1 *}$, A. S. Krishnamoorthy ${ }^{1}$, C. Kavitha ${ }^{2}$, Shwet Kamal ${ }^{3}$, Anil Kumar ${ }^{3}$ and V. P. Sharma ${ }^{3}$ \\ ${ }^{1}$ Department of Plant Pathology, Tamil Nadu Agricultural University, Coimbatore \\ ${ }^{2}$ Department of Fruit Crops, Tamil Nadu Agricultural University, Coimbatore \\ ${ }^{3}$ Directorate of Mushroom Research, Solan, Chambaghat, Himachal Pradesh
}

\begin{abstract}
The present study aimed to selectpotential strainof Volvariella volvacea suitable for outdoor cultivation in different cropping systems like Banana, Maize, Coconut, Coconut+Banana where such suitable microclimate prevails. Among the different strains of V.volvaceatested, the strain Vv-19-06 obtained from Directorate of Mushroom Research, Solan, performed considerably superior with higher bioefficiency of 17.44 and sturdy sporophores at egg stage and storage life of 1.1 days under refrigerated condition.Moreover, the morphogenesis of button stage to matured mushrooms were extended up to 1.8 days and the opened mushroom were retained on the bed for another 1.6 days, which is an added advantage.Cultivation of paddy straw mushroom as intercrop in Banana, Maize, Banana+coconut and Coconut cropping systems proved successful with spawn running completion ranging from 8 to 10.3 days, pinhead formation ranging from 9.3 to 11.6 days and harvestable button/egg stage appeared ranging from 11 to 12.6 days. The bioefficiency was comparatively better in all the cropping systems, which ranged from 19.4 to $20.6 \%$, with a total cropping cycle of 20.5 to 22 days. The indoor cropping system, which requires additional cost for infrastructure, also recorded bioefficiecy of 21.3 in a cropping cycle of 17 days. In all the cropping systems tested, the B:C ratio worked out to be 1:2.3 to 1:2.5 as in indoor cropping system proving that paddy straw mushroomcould be promoted for the outdoor systemin Maize, Banana, Banana +coconut, Coconut cropping systems as intercrop as it fetches additional income to rice-growing farmers.
\end{abstract}

Keywords: Paddy straw mushroom; inter crop; biological efficiency; V.volvacea; outdoor cultivation

\section{INTRODUCTION}

The Paddy straw mushroom (Volvariella volvacea) or Chinese mushroom, well known for its pleasant flavor and taste, ranks sixth among cultivated edible mushrooms and contributes to about 5 to $6 \%$ of world mushroom production (Ahlawat et al., 2011). Another significant feature of this mushroom is its early harvest on $10^{\text {th }}$ day itself, with a shorter cropping cycle of 20 to 22 days compared to any other commercially cultivated mushrooms. Though lot of attempts have been exploited in India (Su and Seth 1940, Thomas et al., 1943; Kandasamy and Ramasamy,1975,Pani and Naik,1998; Sangeetha, 2002, Ahlawat and Tewari,2007; Thiribhuvanamala et al., 2012), commercial cultivation of V.volvacea is still in infant stage because of weak colonization of the substrate by mycelium due to poor ligninolytic enzyme secretory system that ultimately leads to poor yields.
Perusal of literature shows that China is leading in paddy straw mushroom with the production of about 60,00,000 tonnes of mushroom (Wang et al., 2017) where successful cultivation by large number of growers is possible both as indoor and outdoor crop. However, in India, only Odisha state leads in paddy straw mushroom production with an annual production of 8007 tonnes as plenty paddy straw is available coupled with cheap labor and low investment as they cultivate outdoors. Chattisgarh also has started the commercial cultivation of paddy straw mushrooms by small and marginal farmers. This mushroom prefers paddy straw as the best substrate to give optimum yield through perusal of literature shows lot of substrates viz., Banana waste (Zikriyani et al., 2018) cotton waste and oil palm bunch waste (Thiribhuvanamala et al., 2012) prove promising whensubstituted along with paddy straw with a bioefficiency of 19.2 to 21.9 per cent. 
This mushroom prefers an optimum temperature of 32 to $40^{\circ} \mathrm{C}$ with a relative humidity of 75 to $85 \%$ to get stable yields and so mainly cultivated indoors. Due to poor yields, the indoor cultivation of paddy straw mushroom V.volvacea involves a high cost of production and net returns are very low.

Moreover, in Tamil Nadu rice being the major crop, plenty of straw is available even after feeding the cattle is left unused and can be converted to produce paddy straw mushroom especially in delta and coastal areas. In this context, the present study was proposed with an aim to promote commercial cultivation of paddy straw mushroom in the cropping systems like Maize, Banana and Coconut as intercrop (at particular stage of the crop) where such cropping requirements favorable for paddy straw mushroom cultivation are available naturally. Apart from this, the study is focused on the identification and selection of a suitable strain of V.volvacea that can provide maximum yield with quality attributes of sturdy egg-shaped buttons that would have more retention period on beds and could tolerate the fluctuating environmental conditions during the cropping period. Hence, this study would offer scope for the commercial cultivation of paddy straw mushrooms with low investment cost and more returns to the farmers.

\section{MATERIALS AND METHODS:}

\section{Identification of high yielding Volvariella strain}

An experiment was conducted to identify high yielding strain of V.volvcea with good sporophore characters so as to take forward the strain for outdoor cultivation. Five different strains of Volvariella volvacea,Vv-19-01 to Vv-19-06were tested in comparison with TNAU strain of V.volvacea (PS1 collected from Repository culture collection centre of TNAU ) for yield performance in sunken blue polyhouses at TNAU where a temperature of 32 to $36^{\circ} \mathrm{C}$ and relative humidity of $80-85 \%$ was maintained throughout the cropping period. Paddy straw was soaked in water for 6 hours and pasteurized by steaming for 1 hour and each bed was prepared in bundle method with 3 bundles $x$ 4 layers with 1 bundle opened at the top with bed size of $1.5 \times 1.5 \times 1.5$ cu.ft as per the Technical Programme of AICRP Mushroom,2020 using $300 \mathrm{~g}$ paddy straw per bundle with a total of $4 \mathrm{~kg}$ substrate per bed. Spawn was prepared using chopped paddy straw bits mixed with $2 \%$ horse gram powder and autoclaved at $15 \mathrm{lbs}\left(121^{\circ} \mathrm{C}\right)$ for 30 minutes and inoculated with respective V.volvacea cultures. After 15 days when spawn turned to chocolate brown with the formation of chlamydospores, it was used to prepare beds @ 2\% spawning. The Days for Spawn run (DFSR), Days for Pinhead Formation (DFPF), Days for First Harvest (DFFH), Number of fruiting bodies and Average weight of single sporophore and Biological efficiency (\%) were recorded (Yang et al., 2013) .

Biological efficiency (BE) is calculated in \% as Total weight $(\mathrm{kg})$ of harvested mushrooms $x 100$

Total weight (kg) of substrate used

\section{Testing outdoor cultivation of V.volvacea in different cropping systems}

A study was attempted to utilize the existing natural microclimate in cropping systems suitable for cultivation of paddy straw mushroom at $32-40^{\circ} \mathrm{C}$ and relative humidity of 80 to $85 \%$ so as to reduce the cost of production. A trial for the cultivation of paddy straw mushroom, V.volvacea was performed during the month of October2020 under different cropping systems viz., Banana, Maize, Coconut, Coconut + Banana cropping systems.Paddy straw mushroom spawn was prepared in paddy substrate (as mentioned above) and bundle method beds (with 3 bundles $\times 4$ layers with 1 bundle opened at the top with bed size of $1.5 \times 1.5 \times 1.5$ cu.ft. using $500 \mathrm{~g}$ paddy straw per bundle with a total of $6 \mathrm{~kg}$ substrate per bed ). Spawn prepared in paddy straw as substrate with good chlamydospore formation was spawned at the rate of $2 \%$ in the beds. For this purpose, paddy straws were soaked in cold water with $3 \%$ lime (commercial grade Calcium hydroxide) for 6 hours, drained excess water until $60 \%$ moisture and used to prepare bundle method beds as mentioned earlier.

For the cultivation of V.volvacea in the Banana cropping system,fifteen bundle method beds as prepared above were laid in the interspaces of Banana plants (cv.Grand Naine) at the University orchard and covered with polythene sheet for 5 days. Similarly, for the cultivation of V.volvacea in Coconut cropping system, fifteen bundle method beds were prepared as above and laid in the interspaces of coconut trees (three rows) at the university Coconut farm of the university and covered with thin polythene sheets up to 6 days to maintain warmth and humidity. In the Maize cropping system, fifteen bundle method beds were prepared as above and laid in the interspaces of Maize crop $(60 \times 30 \mathrm{~cm})$ (three rows) at university Eastern block farm and covered with thin transparent, recyclable polythene sheet for 5 days. For cultivation of V.volvacea in Coconut + Banana cropping system, fifteen bundle method beds were prepared as above and laid in the interspaces of Coconut + Banana cropping system where Coconut (10 years crop) was cultivated with the spacing of $7 \times 7 \mathrm{~m}$ spacing and Banana crop ( 7 months) was cultivated in the interspaces of coconut (three rows) in farmers field at Ajanur village of 
Coimbatore and covered with thin transparent, recyclable polythene sheet for 5 days

Beds were sprinkled with water twice for 15 days from $6^{\text {th }}$ day onwards after opening of the polythene sheets. In all the conditions, throughout the cropping period, daily bed temperature and relative humidity around the beds and the environmental factors with respect to morning and evening temperature and relative humidity were recorded using digital hygrothermometer. The DFSR, DFPF, DFFH, Number of fruiting bodies and average weight of single sporophore were recorded as above. The different stages of mushrooms include pinhead stage (primordia formation), button/ egg stage, matured/ bell-shaped mushrooms. Biological efficiency (\%) and $\mathrm{B}: \mathrm{C}$ ratio were calculated. For comparison, during the same period, fifteen bundle method beds were prepared as above and placed in blue polyhouses where temperature of 34 to $37{ }^{\circ} \mathrm{C}$ and $\mathrm{RH}$ of 80 to $85 \%$ was maintained. Beds were sprinkled with water twice for 15 days from $6^{\text {th }}$ day onwards. In all the conditions, throughout the cropping period, daily bed temperature and relative humidity around the beds and the environmental factors inside the polyhouse with respect to morning and evening temperature and relative humidity were recorded using digital hygrothermometer. Yield parameters were recorded as described above.

Table 1. Bioefficiency and yield performance of differentVolvariella strains

\begin{tabular}{|c|c|c|c|c|c|c|c|c|c|c|}
\hline Strains & DFSR & DFPF & $\begin{array}{l}\text { DFFH } \\
\text { at egg } \\
\text { stage }\end{array}$ & $\begin{array}{l}\text { Sturdiness } \\
\text { of egg stage } \\
\text { mushroom }\end{array}$ & $\begin{array}{l}\text { Days taken } \\
\text { from egg stage } \\
\text { to bell stage }\end{array}$ & $\begin{array}{l}\text { Av. no. of } \\
\text { fruiting } \\
\text { bodies/ } \\
\text { bed }\end{array}$ & $\begin{array}{l}\text { Average weight } \\
\text { of mushrooms } \\
\text { (g) }\end{array}$ & $\begin{array}{l}\text { Retention of } \\
\text { bell shaped } \\
\text { mushrooms on } \\
\text { beds (days) }\end{array}$ & $\begin{array}{l}\text { Average } \\
\text { yield } \\
\text { /bed } \\
\text { (Kg) }\end{array}$ & $\begin{array}{c}\text { Bioefficiency } \\
(\%)\end{array}$ \\
\hline Vv-19-01 & 8.9 & 9.9 & 11.1 & + & 1.2 & 27.7 & 30.28 & 0.6 & 0.839 & 12.92 \\
\hline Vv-19-02 & 12.4 & 14.5 & 15.2 & + & 0.7 & 25.3 & 23.90 & 0.7 & 0.605 & 9.32 \\
\hline Vv-19-03 & 8.5 & 10.4 & 11.2 & ++ & 0.8 & 27.8 & 36.22 & 1.0 & 1.009 & 15.52 \\
\hline Vv-19-04 & 12.1 & 13.9 & 14.5 & + & 0.6 & 25.2 & 24.78 & 0.6 & 0.625 & 9.60 \\
\hline Vv-19-05 & 13.1 & 14.8 & 15.3 & + & 0.5 & 25.7 & 24.44 & 0.7 & 0.629 & 9.64 \\
\hline Vv-19-06 & 8.7 & 10.4 & 12.2 & +++ & 1.8 & 31.5 & 35.98 & 1.6 & 1.134 & 17.44 \\
\hline PS1 (TNAU ) & 8.0 & 10.0 & 11.2 & + & 0.8 & 32.0 & 33.08 & 0.7 & 1.056 & 16.20 \\
\hline SEd & 0.708 & 0.806 & 1.504 & & & 2.36 & 1.20 & 0.02 & 0.084 & \\
\hline CD (0.05\%) & 1.477 & 1.682 & 3.138 & & & 4.93 & 2.50 & 0.04 & 0.175 & \\
\hline
\end{tabular}

$\begin{array}{llll}\text { Sturdiness of buttons } & \text { + } & \text { : light } \quad++: \text { medium } \quad+++: \text { thick }\end{array}$

\section{Statistical Analysis}

Mean differences of the treatment were evaluated with ANOVA using Duncan's Multiple Range-Test at 5\% significance (Gomez and Gomez, 1984). All the data were statistically analyzed with IRRISTAT (version. 3/93, Biometrics unit, International Rice Research Institute) and consequently interpreted.

Table 2. Performance trial on the out door cultivation of V.volvaceaunder different cropping systems

\begin{tabular}{|c|c|c|c|c|c|c|c|c|c|c|c|c|c|c|c|}
\hline \multirow{2}{*}{ Treatments } & \multirow{2}{*}{$\begin{array}{c}\text { Cropping } \\
\text { systems } \\
\text { /house }\end{array}$} & \multicolumn{2}{|c|}{$\begin{array}{c}\text { Environmental } \\
\text { conditions }\end{array}$} & \multicolumn{2}{|c|}{$\begin{array}{c}\text { Bed } \\
\text { conditions }\end{array}$} & \multirow{2}{*}{$\begin{array}{l}\text { DFSR } \\
\text { (Days) }\end{array}$} & \multirow{2}{*}{$\begin{array}{c}\text { DFPF } \\
\text { (Days) }\end{array}$} & \multicolumn{2}{|c|}{$\begin{array}{c}\text { DFFH } \\
\text { (Days) }\end{array}$} & \multicolumn{2}{|c|}{$\begin{array}{l}\text { Fruiting body } \\
\text { (Average) }\end{array}$} & \multirow{2}{*}{$\begin{array}{c}\text { Av. yield } \\
\text { /bed } \\
\text { (kg) }\end{array}$} & \multirow{2}{*}{$\begin{array}{c}\text { TCP } \\
\text { (Days) }\end{array}$} & \multirow{2}{*}{ BE (\%) } & \multirow{2}{*}{ B:C } \\
\hline & & $\begin{array}{c}\text { Temp. } \\
{ }^{\circ} \mathrm{C}\end{array}$ & $\begin{array}{l}\mathbf{R H} \\
\text { (\%) }\end{array}$ & $\begin{array}{c}\text { Temp. } \\
{ }^{\circ} \mathbf{C}\end{array}$ & $\begin{array}{l}\mathbf{R H} \\
\text { (\%) }\end{array}$ & & & $\begin{array}{l}\text { Egg } \\
\text { stage }\end{array}$ & $\begin{array}{c}\text { Bell } \\
\text { shape }\end{array}$ & $\begin{array}{c}\text { Weight } \\
\text { (g) }\end{array}$ & $\begin{array}{c}\text { Number } \\
\text { (No.) }\end{array}$ & & & & \\
\hline $\mathrm{T} 1$ & Banana & 30.0 & 62.5 & 39.3 & 86.5 & 8.0 & 9.3 & 11.0 & 13.0 & 27.8 & 29.7 & 0.826 & 21.0 & 20.6 & $1: 2.5$ \\
\hline $\mathrm{T} 2$ & Maize & 29.0 & 62.4 & 37.0 & 84.0 & 9.0 & 10.3 & 11.3 & 12.6 & 26.8 & 29.0 & 0.777 & 20.5 & 19.4 & $1: 2.4$ \\
\hline T3 & Coconut & 30.3 & 60.0 & 36.5 & 83.5 & 10.3 & 11.6 & 12.6 & 13.5 & 25.8 & 29.5 & 0.761 & 22.0 & 19.0 & $1: 2.3$ \\
\hline $\mathrm{T} 4$ & $\begin{array}{r}\text { Coconut + } \\
\text { Banana }\end{array}$ & 28.0 & 62.0 & 37.0 & 84.5 & 9.3 & 10.6 & 12.0 & 13.5 & 26.8 & 29.3 & 0.785 & 22.0 & 19.6 & $1: 2.4$ \\
\hline T5 & $\begin{array}{r}\text { Indoor } \\
\text { (polyhouse) }\end{array}$ & 34.0 & 82.7 & 37.3 & 83.7 & 8.0 & 9.5 & 10.5 & 12.0 & 30.1 & 28.3 & 0.851 & 17.0 & 21.3 & $1: 2.5$ \\
\hline & SEd & & & & & 0.25 & 0.28 & 0.24 & 0.18 & 0.32 & 0.26 & 13.3 & & & \\
\hline & $\mathrm{CD}(0.05 \%)$ & & & & & 0.50 & 0.56 & 0.48 & 0.37 & 0.64 & 0.53 & 26.7 & & & \\
\hline
\end{tabular}




\section{RESULTS AND DISCUSSION}

Out of the seven strains of Volvariella volvacea tested, the results showed that strain Vv-19-06 recorded maximum bioefficiency of $17.44 \%$ ( $1.134 \mathrm{~kg} / \mathrm{bed}$ ) followed by $\mathrm{V} v-19-03$ with $15.5 \%$ bioefficiency ( $1.009 \mathrm{~kg} / \mathrm{bed})$ in $6 \mathrm{~kg}$ paddy straw/ bed. The average number of fruiting bodies were maximum in Vv-19-06, Vv-19-03 and Vv-19-01 (31.5, 27.8 and 27.7 numbers) (Table 1).The spawn run completed was earlier and on par with each other in Vv-19-03, Vv-19-06, Vv-19-01 and PS1 ranging from 8 to 8.9 days compared to other strains $V_{V}$ 19-02, Vv-19-04 and Vv-19-05, which took longer days for spawn run completion (12 to 13 days). The pinheads/primordia emerged early in Vv-19-01 on $9^{\text {th }}$ day followed by PS1,Vv-19-03 and Vv-19-06 when compared to other strains (13.9 to 14.5 days). Similarly, the strains Vv-19-01, Vv-19-03 and PS1 produced sporophores at egg/button stage ready for harvest within 11 to 11.5 days whereas $\mathrm{V} v$-1906 took 12 days; however, they were on par with each other. However, the average fruit body weight was maximum in Vv-19-06 and Vv-19-03 and PS1 (35.98g, 36.22 g,33.08g, respectively).The average number of fruiting bodies/ bed was maximum in PS1 (32 numbers) and Vv-19-06 (31.5 numbers). Significantly superior biological efficiency of $17.44 \%$ in Vv-19-06 followed by Ps1 (16.2\%) was recorded.
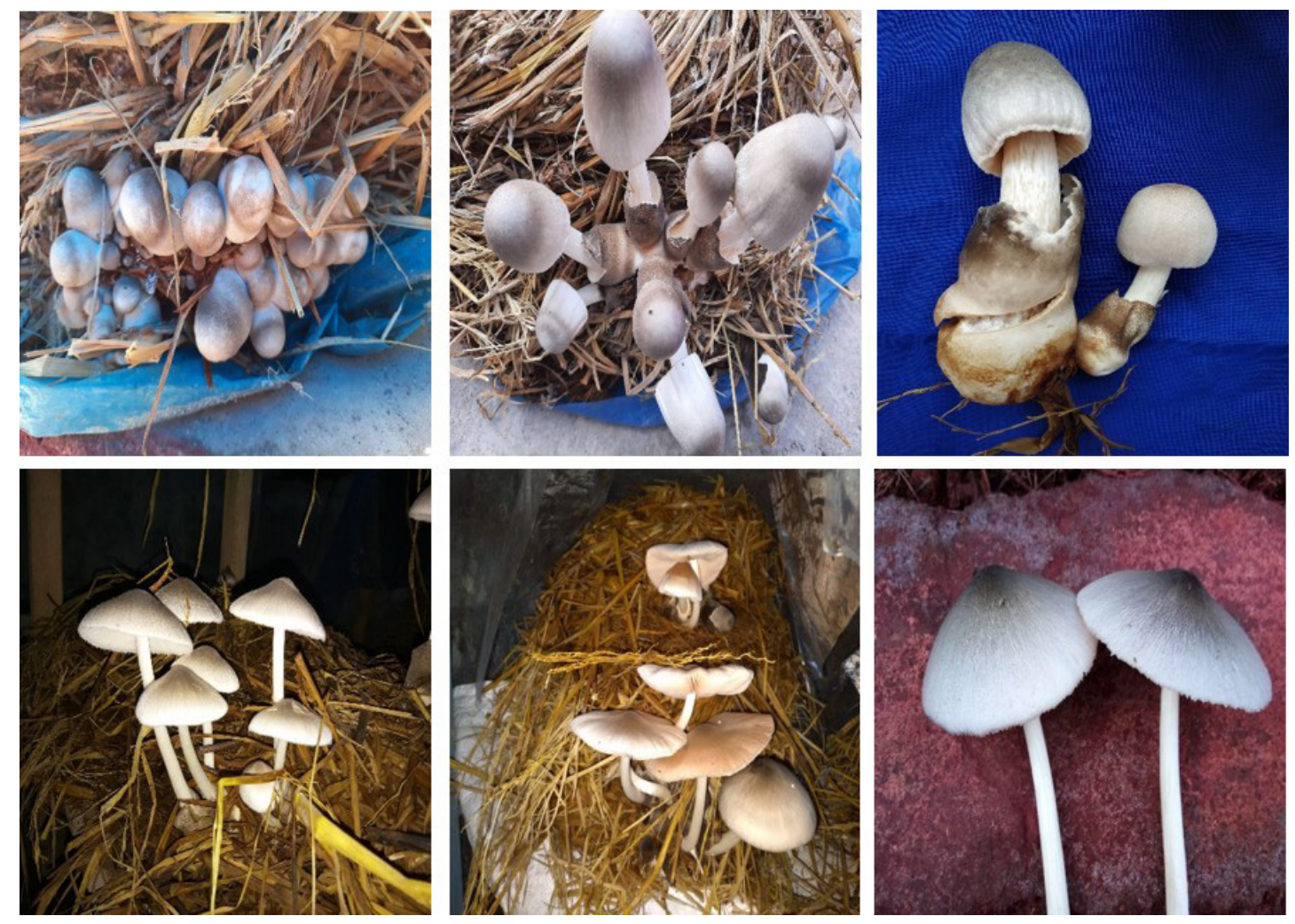

Fig.1. Selected strain Vv-19-06 of Paddy straw mushroom, V.volvacea

Interestingly, the sturdiness of egg stage mushrooms were thick in $\mathrm{V} v$-19-06 compared to PS1 and other strains, followed by Vv-19-03 with medium sturdiness (Fig.1). Sturdiness is an important attribute in the case of $\mathrm{Vv}$-19-06 as noticed by the increased time taken by 1.8 days to open from egg to bell /umbrella shaped sporophores with increased retention of another 1.6 days in the beds. This increased time taken for morphogenesis from egg to bell shape added with more retention time on the beds offers advantage for quality mushrooms compared to other strains where morphogenesis happened quickly and led to over matured sporophores within a short time. Moreover, the egg stage of $\mathrm{Vv-19-06}$ had higher sturdiness due to the thick volva that covered the egg stage sporophores. The sporophores of strain Vv-19-06 that opened after morphogenesis had thick pileus of $0.4 \mathrm{~cm}$ that offered more shelf life of 1 day under room temperature (newspaper bags ) compared to other strains $(0.2$ to $0.37 \mathrm{~cm})$ with shelf life of only 6 hours (data not shown). The strain Vv-19-06 was found highly suitable for commercial cultivation and used for testing its suitability under outdoor cultivation trials.

Though there are about 19 recorded species of Vovariellain India, only three species have been explored for cultivation viz .,V. volvacea (Bull ex Fr.) Sing., V. esculenta (Mass) Sing.,V. diplasia (Berk and Br.) Sing. and among them, V.volvacea is

$107|10-12| 4$ 
preferred owing to its quick growth and significant yield compared to others. Selection of strain isthe foremost factor to be considered for cultivation of paddy straw mushroom as those strains proving better in indoor cultivation fails to perform in outdoor conditions due to fluctuating temperature and relative humidity. In our study, the V.volvacea strain Vv-19-06 produced good chlamydospore formation in spawn and produced sporophores with sturdy buttons and prolonged morphogenesis without deteriorationduring the cropping period that offers scope for outdoor cultivation.

\section{Fig.2. Outdoor cultivation of V.volvacea under different cropping systems}

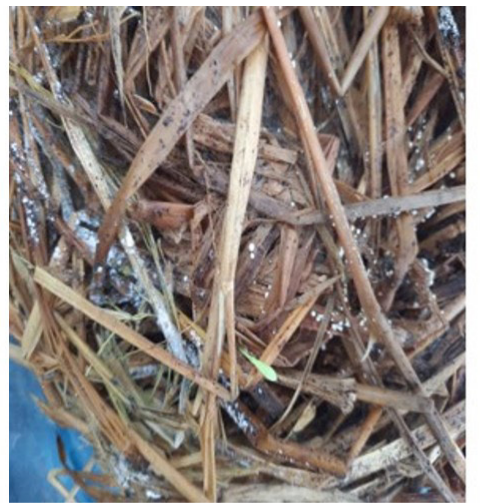

Spawn running to pinhead formation

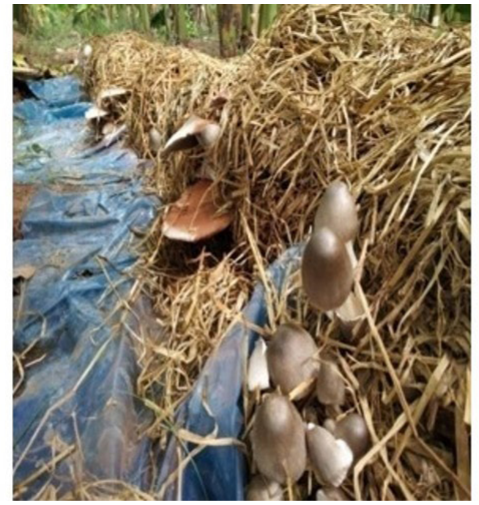

Bell shaped fruiting

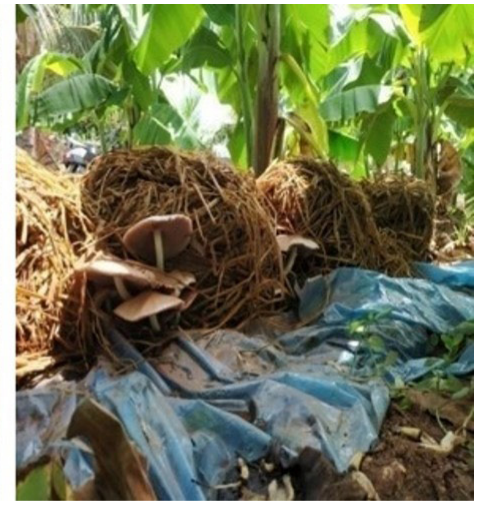

Matured sporophores

\section{Fig.2a Production of V.volvacea in Banana cropping system}

The idea behind the outdoor cultivation of paddy straw mushrooms is to effectively utilize the prevailing natural microclimate in the cropping system to accomplish low investment and get good returns. The cultivation of V.volvacea was attempted during the second week of September to first week of October 2020.in different cropping systems and compared with the indoor cultivation system and the results are presented in Table.2 and Fig.2

The results revealed that in the banana cropping system (T1) the strain Vv-19-06 showed that spawn running was completed on $8^{\text {th }}$ day and pinheads appeared on 9.3 days and egg stage mushrooms developed on $11^{\text {th }}$ day (Fig.2a.). The matured fruiting bodies at bell stage were observed on $13^{\text {th }}$ day. The paddy straw bundle beds were recorded an average bed temperature of $39.3^{\circ} \mathrm{C}$ and relative humidity of $86.5 \%$ throughout the cropping period and the environmental conditions recorded average temperature of $30^{\circ} \mathrm{C}$ and $62.5 \%$ relative humidity. One interesting observation is that the bell/ umbrella stage mushrooms were retained on the bed for another 11 hours, which might be due to the high humidity prevailing in the banana cropping system. So there is enough time of 2 days from egg stage to bell / umbrella-shaped stage, which is advantageous to the farmer to harvest mushrooms depending upon demand as in case of oyster and milky mushroom. On average 29.7 fruiting bodies with an average weight of $27.8 \mathrm{~g}$ per sporophore was obtained with biological efficiency (BE) of $20.6 \%(0.826 \mathrm{~kg} / \mathrm{bed})$ which accounted to C:B ratio of 1: 2.5 (Fig.1). The total cropping cycle (TCP) was observed as 21 days in three harvests.

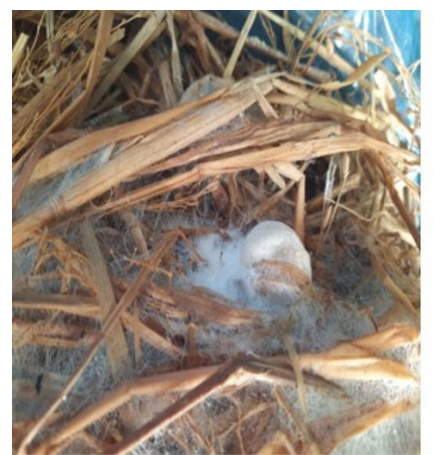

Spawn running

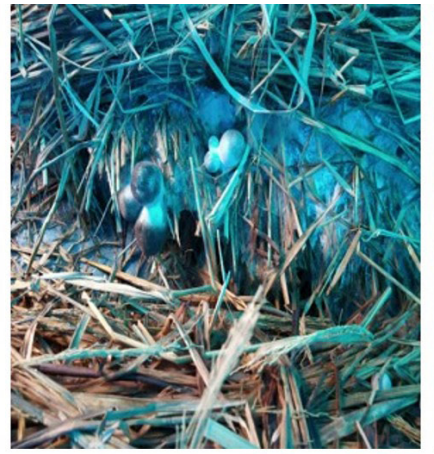

Egg stage buttons emergence

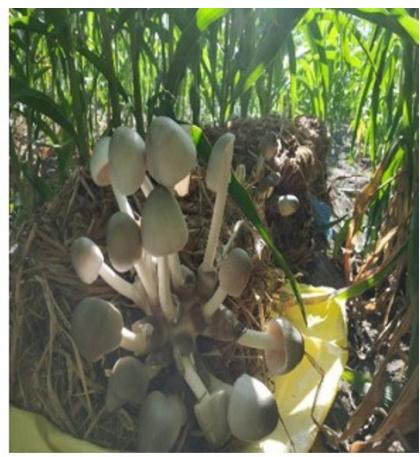

Flush of mushrooms

Fig.2b. Production of V.volvacea in Maize cropping system 
Similarly, in the Maize cropping system (T2), the spawn running of strain $\mathrm{Vv-19-06}$ as completed on $9^{\text {th }}$ day and pinheads appeared on 10.3 days and egg stage mushrooms developed on 11.3days and bell-shaped mushrooms were harvested up to 12.6 days and were able to retain on the bed for another 9 hours with a total cropping cycle (TCP) of 20.5 days (Fig.2b). On an average 29.0 fruiting bodies with an average weight of $26.8 \mathrm{~g}$ was obtained with biological efficiency (BE) of $19.4 \%(0.777 \mathrm{~kg} /$ bed),accounting to $\mathrm{C}: \mathrm{B}$ ratio 1:2.4 in three harvests. An average bed temperature of $37^{\circ} \mathrm{C}$ and $\mathrm{RH}$ of $84.0 \%$ and environmental conditions of Maize field recorded an average temperature of $29^{\circ} \mathrm{C}$ and $\mathrm{RH}$ of $62.4 \%$ was recorded during the cropping period.

Also, in coconut cropping system (T3), the spawn running of strain Vv-19-06 was completed on 10.3 day and pinheads appeared on 11.6 days and egg stage mushrooms developed on 12.6 days and bell-shaped mushrooms were harvested up to 13.5 days and were able to retain on the bed for another 7 hours without any deterioration (Fig.2c). On an average 29.5 fruiting bodies with an average weight of $25.8 \mathrm{~g}$ per sporophore was obtained with biological efficiency (BE) of $19.0 \%(0.761 \mathrm{~kg} / \mathrm{bed})$ and total cropping cycle (TCP) of 22 days with C:B ratio accounting to $1: 2.3$ in three harvests. The bed average temperature of $36.5^{\circ} \mathrm{C}$ and relative humidity of $83.5 \%$ and environmental conditions in the coconut field recorded an average temperature of $30.3^{\circ} \mathrm{C}$ and $60 \% \mathrm{RH}$ during the cropping period.

In Coconut+Banana cropping system (T4), the strain Vv-19-06 showed that spawn running was completed on 9.3 day and pinheads appeared on 10.6 days and egg stage mushrooms developed on $12^{\text {th }}$ day and bell shaped mushrooms were harvested up to 13.5 days and were able to retain on the bed for another 8 hours with a total cropping cycle (TCP) of 22 days (Fig.2d.). On an average 29.3 fruiting bodies with an average weight of $26.8 \mathrm{~g}$ was obtained with biological efficiency (BE) of $20.3 \%(0.785 \mathrm{~kg} /$ bed),accounting to $\mathrm{C}: \mathrm{B}$ ratio accounting to $1: 2.5$ in three harvests. An average bed temperature of $37^{\circ} \mathrm{C}$ and $\mathrm{RH}$ of $84.5 \%$ and field environmental conditions with average temperature of $28^{\circ} \mathrm{C}$ and $62 \% \mathrm{RH}$ was recorded during the cropping period.
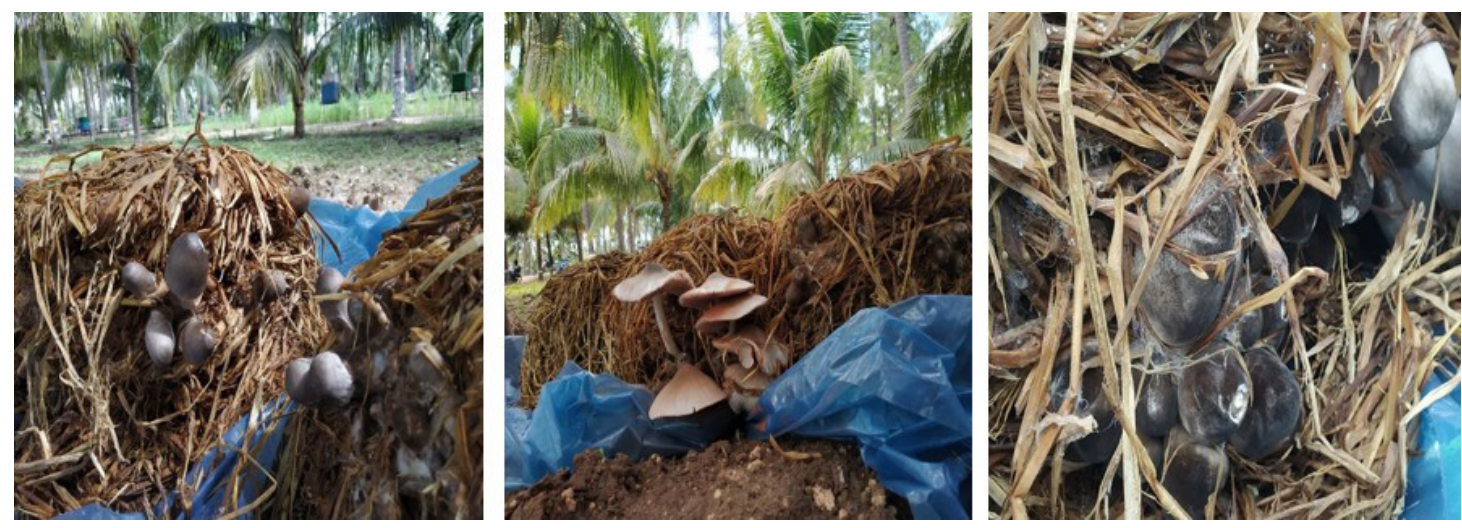

Fig.2c.Production of V.volvacea in Coconut cropping system

The indoor cultivation (T5) of V.volvacea strain Vv-19-06 in polyhouses the spawn running was completed on $8^{\text {th }}$ day and pinheads appeared on 9.5 days and egg stage mushrooms developed on 10.5 days and bell-shaped mushrooms were harvested up to 12 days and were able to retain on the bed for another 10 hours without any deterioration. On an average 28.3 fruiting bodies with an average weight of $30.1 \mathrm{~g}$ per sporophore was obtained with biological efficiency (BE) of $21.3 \%(0.851 \mathrm{~kg} / \mathrm{bed})$ and total cropping cycle (TCP) of 17 days with C:B ratio accounting to $1: 2.5$ in three harvests. The bed average temperature of $37.3^{\circ} \mathrm{C}$ and relative humidity of $83.7 \%$ and environmental conditions inside polyhouse recorded average temperature of $34^{\circ} \mathrm{C}$ and $82.7 \% \mathrm{RH}$ during the cropping period.

For maximizing yield in paddy straw mushroom, suitable strain selection is important that grows quickly and colonizes the substrate, thereby leading to the production of pinheads under favorable environmental conditions. However,the tropical plains of India offer suitable climatic conditions with a prolonged growing season from February to October, providing an ideal temperature for the cultivation of V.volvacea. For year-round cultivation of paddy straw mushrooms, the requirement of additional cost for the erection of poly houses or shade nets is the disadvantage of indoor cultivation method (Mahapatra etal., 2020), which involves high investment and low returns.So as in our study the microclimate available in cropping systems like Maize, Banana and coconut is found to be quite suitable with 35 to $37^{\circ} \mathrm{C}$ with relative humidity of 80 $85 \%$ throughout the cropping period. Earlier outdoor cultivation of paddy straw mushroom (Volvariella volvacea) was experimented in maize-based cropping system (Krishnamoorthy et al.,2005) and

$107 \mid 10-12$ | 6 
in the banana field in Orissa (Pani and Naik ,1998) . Thuc et al.,(2020) has attempted the outdoor cultivation of paddy straw mushroom for poverty alleviation in Vietnam, Philippines and Thailand. However, few researchers pointed out that outdoor system of cultivation led to lower yields compared to indoor cultivation in polyhouses, bamboo and thatched roofs (Rajapakse,2011; Thakur and Yadav,2006) due to fluctuation in temperature and humidity. But in our study, the net returns were on par with the indoor cultivation since there are not many alternations in climatic conditions within the cropping system except for the shorter cropping period earlier by three days in the indoor system. There were no differences noticed in the quality of mushrooms with respect to number of harvested mushrooms and their weight. Moreover, as the farmer utilizes the labor taking care of the cropping system, investment is less.Among the cropping systems, Banana and Coconut+ Banana followed by Maize cropping system proved successful for commercial cultivation of paddy straw mushroom provided good quality spawn must be available. It is inferred that in Maize cropping system (45 days to 75 days of maize crop) and in Banana cropping systems ( $7^{\text {th }}$ to $9^{\text {th }}$-month banana crop stage) and in coconut+ Banana cropping system (7th to 9thmonth banana crop stage), about 4 crops of paddy straw mushroom and in coconut cropping system about 10 to 12 crops of paddy straw mushroom can be planned which will provide additional income to farmers. Also, the spent mushroom substrate after harvest can be converted into biomanure and incorporated into the field.

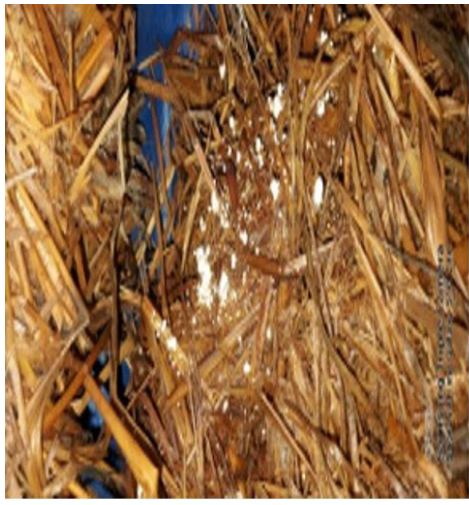

Pinhead formation

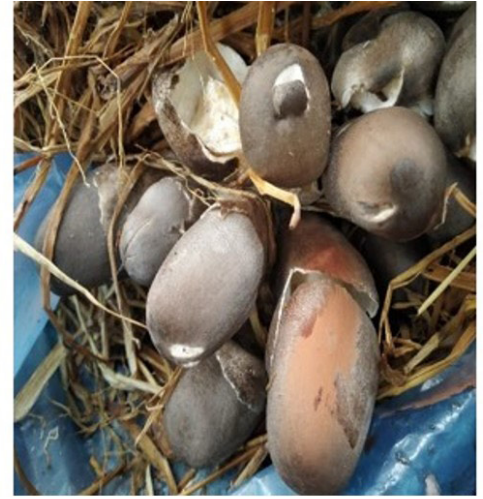

Egg stage sporophores

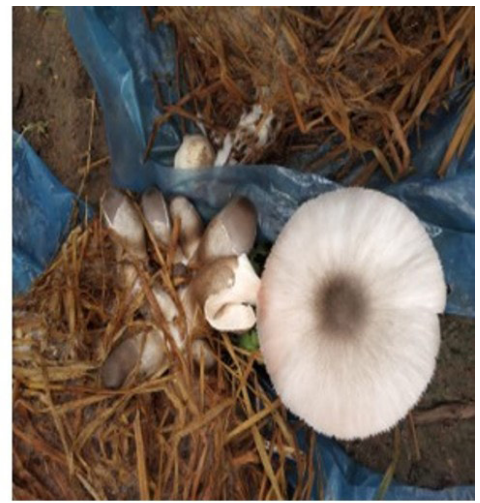

Egg stage to matured

Fig.2d.Production of V.volvacea in Coconut + Banana cropping system

\section{CONCLUSION}

This study offers scope and attracts the farming community for taking up cultivation of paddy straw mushroom as an intercrop in Banana, Maize,Coconut+ Banana and Coconut cropping systems without any additional preliminary investment and provides good net returns. No other vegetable other than V.volvacea has shorter crop duration and certainly,promotion of commercial cultivation by a large group of farmers not only provides additional income but also introduces another delicious edible mushroom to the consumers.

\section{ACKNOWLEDGMENT}

The authors acknowledge the financial support provided by ICAR (AICRP) on Mushroom, Directorate of Mushroom Research, Solan and the research facilities provided by the university to carry out the study.

\section{REFERENCES}

Ahlawat, O.P., Singh,R. and S.Kumar 2011. Evaluation of Volvariella volvacea strains for yield anddiseases/ insect-pests resistance using composted substrate of paddy straw and cotton mill wastes.Indian J. Microbiol., 51(2):200-205.

Ahlawat. O.P.and R.P. Tewari 2007. Cultivation technology of paddy straw mushroom (Volvariella volvacea).Technical Bulletin, National Research Centre for Mushroom, Chambaghat, Solan (H.P.), $36 \mathrm{p}$.

Krishnamoorthy, A.S.,Thiribhuvanamala, G.,Shanthi,K ., and T. Marimuthu 2005. Outdoor cultivation of paddystraw mushroom as inter-crop in Maize field. Mushroom Research, 14(1): -9-12

Mahapatra , N.,Rahman, F.H. Mishra ,P., Sahoo , T.R., Sahoo ,P.K and S. N. Mishra.2020. Assessment of Scope and Efficiency of Off-Season Rice Straw Mushroom (Volvariella volvacea L.) Cultivation in Coastal Odisha. Current Journal of Applied Science and Technology,39(27): 28-34

Pani BK, Naik RP.1998. Yield performance of rice straw mushroom (Volvariella sp.) under natural climaticconditions in Odisha. Environment and Ecology,16(4):968- 969. 
Rajapakse P. 2011.New cultivation technology for rice straw mushroom (Volvariella volvacea). in:Proceedingsof $7^{\text {th }}$ Interntionational Conference on Mushroom Biology and Mushroom Products (ICMBMP7), Arcachon, France., 446- 451 pp

Ramasamy,K and T.K.Kandaswamy 1975.Effect of spawn media on spawn quality and yield of Volvariellavolvacea. Massee. In: $16^{\text {th }}$ Ann. Microbiol. Conf. Assoc. Microbiologists, Rishikesh,India. p.76

Sangeetha, G .2002. Exploring the possibilities of increasing the yield potential of paddy strawmushroom.M.Sc. (Ag.) Thesis. Tamil Nadu Agric. Univ. Coimbatore. 102 p.

Su UT, Seth L N (1940). Cultivation of straw mushroom. Indian farming. 1:332-333.

Thomas, K.M., Ramakrishnan, T.S and L. Narasimhan. 1943. Paddy straw mushroom. Madras Agric. J.,31:57-59.

Thakur, M.P. and V. Yadav 2006.Modern Technique of cultivation of rice straw mushroom in a commercialscale. In: Emerging area of Mushroom Diversity, Production and Postharvest Developments. (Eds.)Department of Plant Pathology, Indira Gandhi Agricultural University, Raipur, India.10-25 pp.

Thiribhuvanamala G., Krishnamoorthy,A.S., Manoranjitham, K., Praksasm, V. and K.Sakthivel.
2012. Improvedtechniques to enhance the yield of paddy straw mushroom (Volvariella volvacea) for commercialcultivation. Afr.J. Biotechnol. 11(64): 12740-12748

Thomas, .KM., Ramakrishnan, T.S.and L. Narasimhan 1943. Paddy straw mushroom. Madras Agric.J.,31:57-59

Thuc, L.V.,Corales,R.G., Sajor,J.T.,Truc,N.T.T.,Hien,P. H.,Ramos,,R.E., Bautista,E.,.Tado,C.J.M.,Ompa d,V.,Son, D.T. and N.V. Hung.2020. Rice-Straw Mushroom Production. In: Sustainable Rice straw managementM.Gummertet al. (eds.),Vietnam Press,93-108 pp.

Wang,R., Cao,H., J Zhang,J. and T.Qi.2017.Scientific Explorations and Commercial Sales of the StrawMushroom Volvariella volvacea (Bull.) Singer in Republican China: A Brief Review. Indian Journal of History of Science, 52 (1): 95-101

WenJie Yang, FengLing Guo, and ZhengJie Wan 2012.. Yield and size of oyster mushroom grown on rice/wheatstraw basal substrate supplemented with cotton seed hull. Saudi J. Biol.Sci., 20(4): 333-338.

Zikriyani H., Saskiawan, I and W. Mangunwardoyo 2018. Utilization of agricultural waste for cultivation ofpaddy straw mushrooms (Volvariella volvacea (bull.) singer 1951). Intl. J. Agric. Technol.,14(5):805-814 